Abstract 49 Table 2 Summary of LDL-C values for those patients who completed CR in 2019, stratified by treatment guidline and risk category Table 3: Table displaying the LDL-C level attainment for those patients who completed CR in 2019, stratified by guidelines used. The number of patients for whom LDL-C data prior to commencement to commencing CR is given, with percentage of row total in brackets. The mean measured LDL-C level prior and following completion of cardiac rehab is given with $95 \%$ confidence intervals for the mean in brackets. The number of patients who met their absolute LDL-C category for their specified risk category is displayed with row percentage displayed in brackets. The percentage at reduction of LDL-C from measured or calculated baseline LDL-C is given, with $95 \%$ confidence intervals for the mean displayed in brackets. The number of patients who achieved an over 50\% reduction in their LDL-C level when compared to their measured or calculated baseline LDL-C level is given with row percentage in brackets, The number of patients who met their LDL-C guidelines as defined by their contemporary guidelines is displayed with row percentage in brackets. For the 2016 cohort, this required achievement of a reduction of LDL-C below an absolute target, and for those at very high and high risk, a relative reduction of at least $50 \%$ LDL-C when compared to measured or calculated baseline lipids. For the 2019 cohort, both of these criteria must be satisfied.

\begin{tabular}{|c|c|c|c|c|c|c|c|c|}
\hline $\begin{array}{l}\text { Risk } \\
\text { Category }\end{array}$ & $\mathrm{N}$ & $\begin{array}{l}\text { Baseline } \\
\text { LDL-C } \\
\text { Available }\end{array}$ & $\begin{array}{l}\text { LDL-C Pre- } \\
\text { CR }\end{array}$ & $\begin{array}{l}\text { LDL-C Post- } \\
\text { CR }\end{array}$ & $\begin{array}{l}\text { Absolute } \\
\text { LDL-C } \\
\text { Target Met }\end{array}$ & $\begin{array}{l}\text { \% LDL-C } \\
\text { Red. from } \\
\text { baseline }\end{array}$ & $\begin{array}{l}>50 \% \\
\text { Red. LDL- } \\
\text { C }\end{array}$ & $\begin{array}{l}\text { Guideliı } \\
\text { Achiev€ }\end{array}$ \\
\hline \multicolumn{9}{|l|}{$\begin{array}{l}2016 \\
\text { Guidelines }\end{array}$} \\
\hline Very High & 99 & $76(77)$ & $\begin{array}{l}2.72(2.48- \\
2.97)\end{array}$ & $\begin{array}{l}1.67(1.52- \\
1.82)\end{array}$ & $61(62)$ & $61(56-66)$ & $49(70)$ & $73(73)$ \\
\hline High & 2 & $1(50)$ & $4.03\left(\mathrm{NA}^{*}\right)$ & $4.5\left(\mathrm{NA}^{*}\right)$ & $1(50)$ & 70 (NA*) & $1(100)$ & $1(50)$ \\
\hline Moderate & 11 & & $\begin{array}{l}2.69(1.33- \\
4.05)\end{array}$ & $\begin{array}{l}0.95((-0.9)- \\
2.82)\end{array}$ & $8(73)$ & & & $8(72)$ \\
\hline Low & 0 & & & & & & & \\
\hline Subtotal & 112 & $81(72)$ & $\begin{array}{l}2.70(2.46- \\
2.93)\end{array}$ & $\begin{array}{l}1.64(1.49- \\
1.79)\end{array}$ & $70(63)$ & $61(56-66)$ & $50(65)$ & $82(73)$ \\
\hline \multicolumn{9}{|c|}{2019 Guidelines } \\
\hline Very High & 43 & $30(70)$ & $\begin{array}{l}3.34(3.01- \\
3.66)\end{array}$ & $\begin{array}{l}2.86(2.39- \\
3.34)\end{array}$ & $21(49)$ & $50(40-61)$ & $11(37)$ & $18(42)$ \\
\hline High & 2 & $2(100)$ & 2.91 (NA*) & 4.81 (NA*) & $1(50)$ & $\begin{array}{l}13.92 \\
\left(\mathrm{NA}^{*}\right)\end{array}$ & $0(0)$ & $0(0)$ \\
\hline Moderate & 5 & & $\begin{array}{l}3.45(1.56- \\
5.34)\end{array}$ & $\begin{array}{l}2.25(1.01- \\
3.48)\end{array}$ & $3(60)$ & & & $3(60)$ \\
\hline Low & 1 & & & & $1(100)$ & & & $1(100)$ \\
\hline Subtotal & 51 & $37(73)$ & $\begin{array}{l}2.83(2.41- \\
3.25)\end{array}$ & $\begin{array}{l}1.83(1.41- \\
2.25)\end{array}$ & $26(51)$ & $48(37-59)$ & $11(34)$ & $22(43)$ \\
\hline \multicolumn{9}{|l|}{ All Patients } \\
\hline Very High & 142 & $108(76)$ & $\begin{array}{l}2.68(2.48- \\
2.88)\end{array}$ & $\begin{array}{l}1.60(1.47- \\
1.72)\end{array}$ & $82(58)$ & $58(53-63)$ & $68(67)$ & $91(64)$ \\
\hline High & 4 & $3(75)$ & $\begin{array}{l}3.28 \text { (1.56- } \\
5.00)\end{array}$ & $\begin{array}{l}2.43(1.02- \\
3.84)\end{array}$ & $2(50)$ & $32\left(N^{*}\right)$ & $1(33)$ & $1(25)$ \\
\hline Moderate & 16 & & $\begin{array}{l}3.02(2.23- \\
3.80)\end{array}$ & $\begin{array}{l}2.43(1.91- \\
2.94)\end{array}$ & $11(69)$ & & & $11(69)$ \\
\hline Low & 1 & & & & $1(100)$ & & & $1(100)$ \\
\hline Total & 163 & $118(72)$ & $\begin{array}{l}2.72(2.52- \\
2.91)\end{array}$ & $\begin{array}{l}1.69(1.57- \\
1.82)\end{array}$ & 96 (59) & $57(52-62)$ & $61(52)$ & $104(64$ \\
\hline
\end{tabular}

'Baseline lipids do not refer to 'LDL-C pre-rehab' column, but instead the measured LDL-C level for those not on LLT (or the calculated LDL-C level of a patient. adjusted for LLT effect), prior to commencing CR.CR- Cardiac Rehabilitation

were compliant with the guidelines for their risk category (43\% vs $73 \%, \mathrm{p}<0.005)$.

Conclusions Both high intensity statin therapy and ezetimibe are under-prescribed. Fewer patients are meeting the lower absolute LDL-C targets set out in the 2019 ESC guidelines. For those at high risk, determining the reduction in LDL-C from baseline reveals even those meeting their absolute LDL-C targets may still be undertreated.

\section{WHICH LIFESTYLE BEHAVIOURS SHOULD WE BE FOCUSING ON AND HOW DO THEY RELATE TO BNP IN PRE-CLINICAL HEART FAILURE?}

1,2,3B Wong, ${ }^{2} \mathrm{~A}$ McDermot, ${ }^{3} \mathrm{P}$ Creechan, ${ }^{1} \mathrm{~A}$ Radhakrishna, ${ }^{2} \mathrm{~S}$ Muhamme, ${ }^{1} \mathrm{~A}$ Brennan, ${ }^{2} \mathrm{~A}$ Moore, ${ }^{1,2,3} \mathrm{M}$ Ledwidge, ${ }^{1,2,3} \mathrm{~K}$ McDonald. 'St Vincent's University Hospital, Dublin, Ireland; ${ }^{2}$ Heartbeat Trust, Dublin, Ireland; ${ }^{3}$ University College Dublin School of Medicine, Dublin, Ireland

10.1136/heartjnl-2021-ICS.50

Background Heart failure (HF) prevention is a central component in our strategy against the growth in prevalence of this syndrome. This strategy comprises the use of specific therapies such as Renin-Angiotensin-Aldosterone System modifying therapies and more recently Sodium GLucose Transporter-2 inhibitors, but also relies on adoption of good cardiovascular (CV) lifestyle measures. These are encapsulated by Life's Simple 7 (LS7). LS7 include: not smoking, a healthy BMI,

Simple Bar Count of Total Life's Simple 7 Score

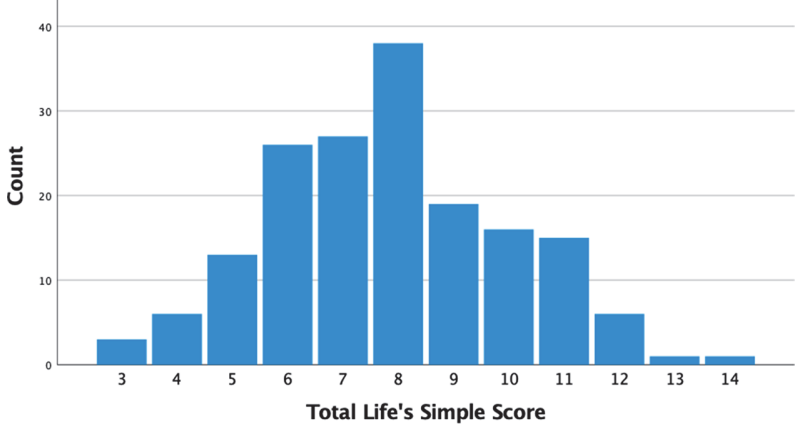

Abstract 50 Figure 1 Composite of life's simple 7 frequency 
physical activity (PA) and diet, as well as blood glucose, blood pressure (BP) and cholesterol control. Adoption of LS7 has been shown to reduce CV risk. Adherence to LS7 is unclear in patients at risk for HF and awareness of these data, would help focus be placed in areas of most need. In addition, it is unclear how this score relates to natriuretic peptide (BNP) levels which remain the most powerful predictor of risk for incident of HF.

Method Data were collected on 172 consecutive patients from STOP-HF Unit (a screening and treatment service for pre- clinical HF). Table 1 demonstrates LS7 scoring table with the higher the score (out of $0,1,2$ ), the better the healthy behaviour. Statistical analysis was undertaken using SPSS V.27. Descriptive and frequency analyses were performed. BNP was non-parametric and Spearman's rho test was performed.

Results There were 76 (44.2\%) females and 96 (55.8\%) males with a mean age of 70 (SD 10.3). Mean LS7 score was 7.9 (SD 2.2) (figure 1) and median BNP was 29 (SD 80). Elevated BP (93\%), elevated BMI (84.1\%) and lack of PA $(64.1 \%)$ were the most common unhealthy behaviours. Not
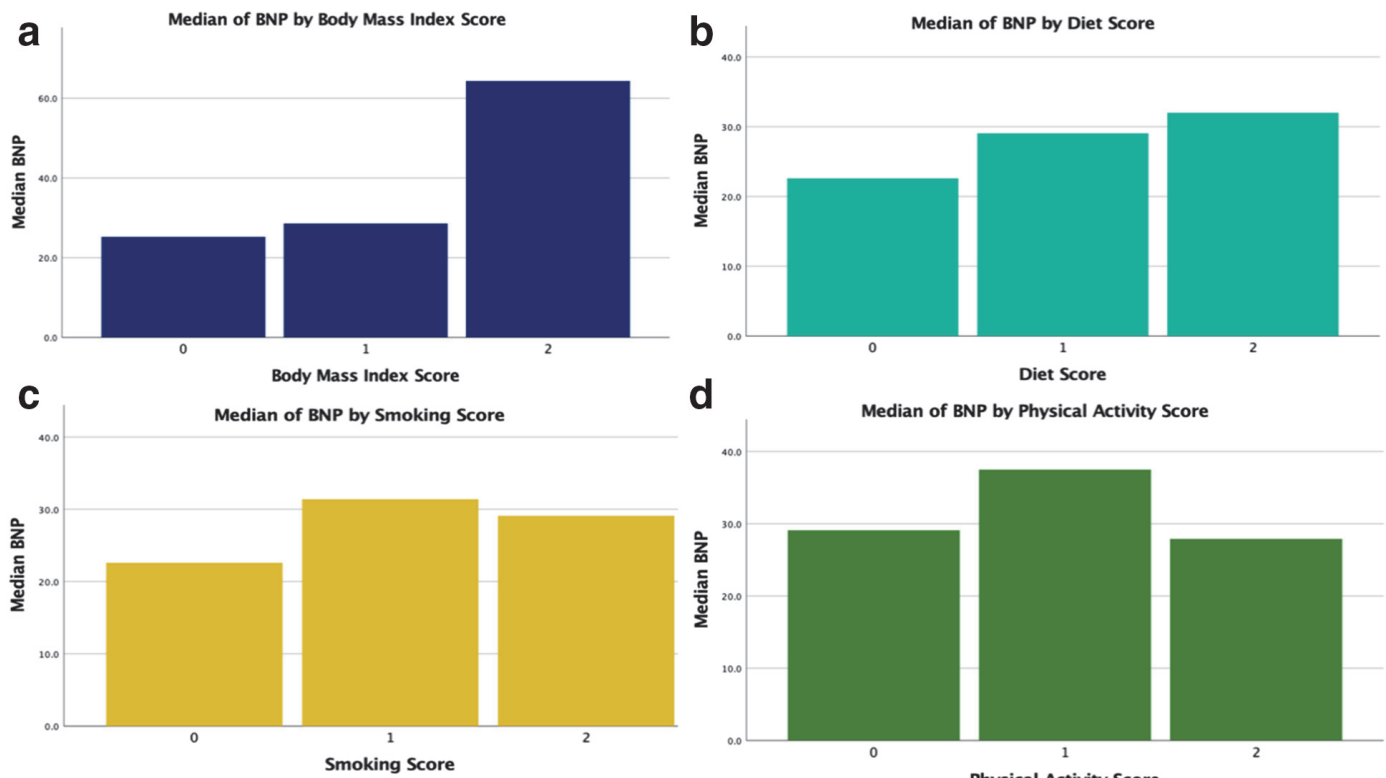

d Median of BNP by Physical Activity Score
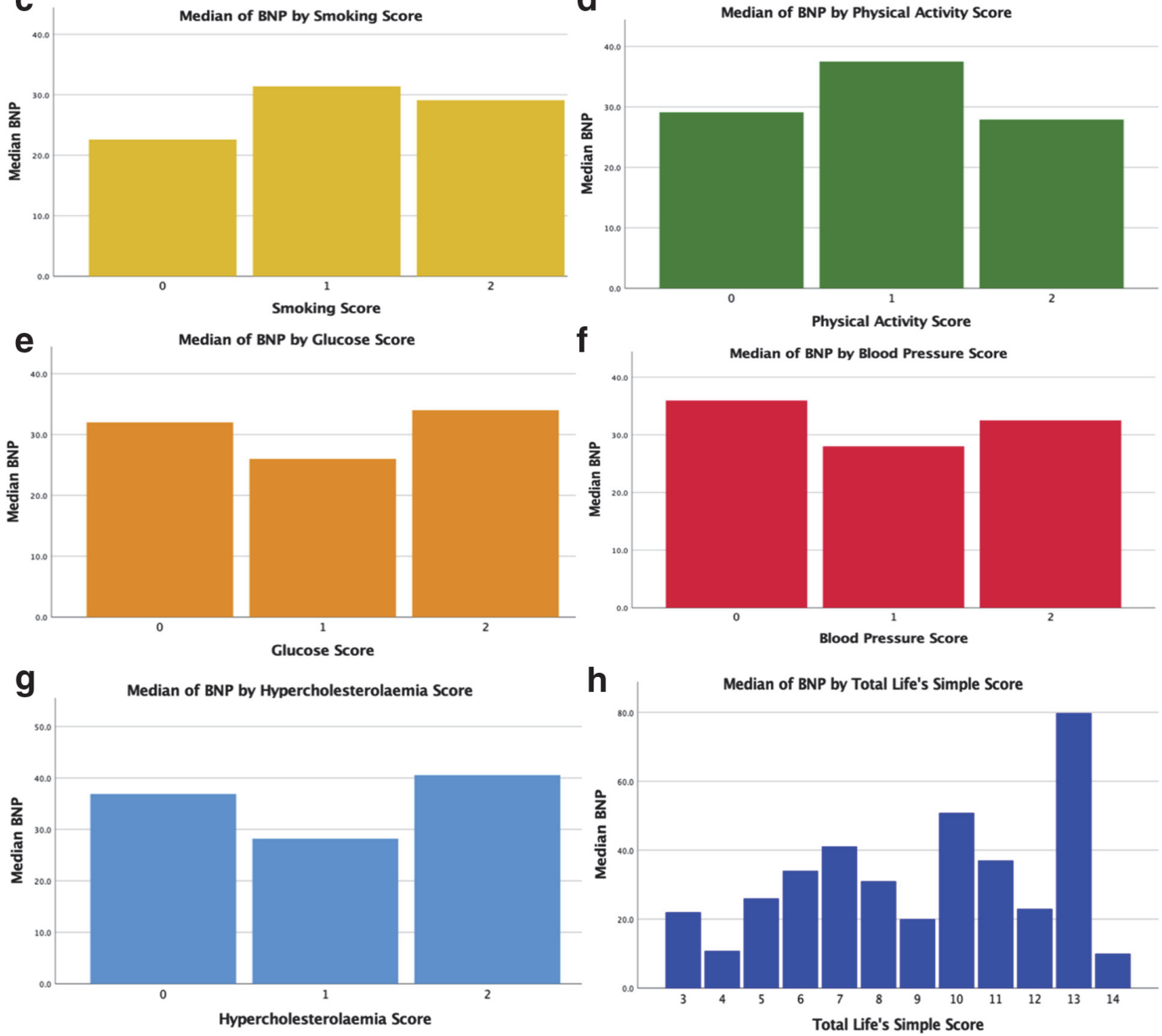

Abstract 50 Figure 2 Healthy behaviours and their correlation with BNP a. BMI in relation to median BNP. A Score of 2 ( Normal BMI) showed statistically higher levels of BNP compared to a BMI score of 0 or 1 (overweight or obese).

b. Diet Score in relation to median BNP. No significant correlation.

c. Smoking score in relation to median BNP. No significant correlation.

d. Physical Activity Score in relation to median BNP. No significant correlation.

e. Glucose Score in relation to median BNP. No significant correlation.

f. Blood Pressure Score in relation to median BNP. No significant correlation.

g. Hypercholesterolaemia in relation to median BNP. No significant correlation.

h. Composite of Life's Simple 7 heathy behaviours with BNP. No significant correlation. 
Abstract 50 Table 1 Life's simple 7 scoring chart

\begin{tabular}{|c|c|c|c|}
\hline Component & Ideal (2 Points) & Intermeciate (I Poht $)$ & Poor (0 Points) \\
\hline Smoking & Never or former $>1$ year & Former $\leq 1$ year & Current \\
\hline Healthy diet score* & 4 to 5 points & 2 to 3 points & 0 to 1 points \\
\hline Physical activity ${ }^{\dagger}$ & $\begin{array}{l}\geq 4 \text { bouts per week of intense physical } \\
\text { activity surficicent to work up a sweat }\end{array}$ & $\begin{array}{l}1 \text { to } 3 \text { bouts per week of interse physical } \\
\text { activity suffcient to work up a sweat }\end{array}$ & $\begin{array}{l}\text { No intense physical activity } \\
\text { sufficent to work up a sweat }\end{array}$ \\
\hline Body mass index & $<25 \mathrm{~kg} / \mathrm{m}^{2}$ & 25 to $29.9 \mathrm{~kg} / \mathrm{m}^{2}$ & $230 \mathrm{~kg} / \mathrm{m}^{2}$ \\
\hline Blood pressure & $<120 / 800 \mathrm{~mm}$ Hg untreated & $\begin{array}{l}\text { SBP } 120 \text { to } 139 \text { or DSP } 80 \text { to } 89 \mathrm{~mm} \text { Hg } \\
\text { or treated to ideal levell }\end{array}$ & $\mathrm{SBP} \geq 140$ or DBP $\geq 90 \mathrm{~mm} \mathrm{Hg}$ \\
\hline Total cholesterol & $<5.18 \mathrm{mmolL}(<200 \mathrm{mg} / \mathrm{dLL})$ untreated & $\begin{array}{l}5.18 \text { to } 6.19 \mathrm{mmol} \text { (200 to } 239 \mathrm{mg} / \mathrm{dl}) \\
\text { or treated to ideal level }\end{array}$ & $26.22 \mathrm{mmolL}$ (2240 mg/dL) \\
\hline Fasting gluoose & $<5.55 \mathrm{mmol}(<100 \mathrm{mg} / \mathrm{dLL}$ ) untreated & $\begin{array}{l}5.55 \text { to } 6.94 \mathrm{mmoll} \text { (100 to } 125 \mathrm{mg} / \mathrm{cl} \text { ) } \\
\text { or treated to ideal level }\end{array}$ & $\geq 6.99 \mathrm{mmolL}(\geq 126 \mathrm{mg} / \mathrm{dL})$ \\
\hline
\end{tabular}

(Table adapted from REGARDS study and AHA guidelines)

Guide:

Ask the patient on an average day what is their intake of each of the followin

*Healthy diet score $=(1)$ Fruits and vegetables $\geq 4.5 \mathrm{cups} /$ day. (2) Fish $\geq 200$ g ( 2 medium portions)per week (3) fibre rich whole grains (kamut, teff, pearl barley, quinoa, whole-wheat pasta, buckwheat, oatmeal, whole wheat bread, and brown rice) $3 \times 30$ gram (1 ounce) portions/day. (4) salt $<1500 \mathrm{mg} /$ day $(2 / 3$ a teaspoon), (5) sugar sweetened beverages ( 1 litre/week).

tPhysical activity is measured by asking the question "How many times per week do you undertake moderate intensity of physical activity lasting 30 minutes, enough to work up a sweat, where you may be able to talk, but not sing?"

For blood pressure where possible, please use home measurements or ABPM if performed. For non-diabetic patients, assume fasting glucose is normal unless HbA1c is elevated.

Total score.

14

\begin{tabular}{|c|c|c|}
\hline \multicolumn{3}{|c|}{$\begin{array}{c}\text { Life's Simple } 7 \text { and Their Frequencies in a Pre- } \\
\text { Clinical Heart Failure Population }\end{array}$} \\
\hline & & Percentage \\
\hline \multirow[t]{3}{*}{ Body Mass Index Score } & 0 & $39.0 \%$ \\
\hline & 1 & $44.2 \%$ \\
\hline & 2 & $16.9 \%$ \\
\hline \multirow[t]{3}{*}{ Blood Pressure Score } & 0 & $29.7 \%$ \\
\hline & 1 & $63.4 \%$ \\
\hline & 2 & $7.0 \%$ \\
\hline \multirow[t]{3}{*}{ Diet Score } & 0 & $5.2 \%$ \\
\hline & 1 & $48.3 \%$ \\
\hline & 2 & $46.5 \%$ \\
\hline \multirow[t]{3}{*}{ Glucose Score } & 0 & $29.1 \%$ \\
\hline & 1 & $32.6 \%$ \\
\hline & 2 & $38.4 \%$ \\
\hline \multirow[t]{3}{*}{ Hypercholesterolaemia Score } & 0 & $4.7 \%$ \\
\hline & 1 & $77.9 \%$ \\
\hline & 2 & $17.4 \%$ \\
\hline \multirow[t]{3}{*}{ Physical Activity Score } & 0 & $45.9 \%$ \\
\hline & 1 & $18.2 \%$ \\
\hline & 2 & $35.9 \%$ \\
\hline \multirow[t]{3}{*}{ Smoking Score } & 0 & $9.9 \%$ \\
\hline & 1 & $2.9 \%$ \\
\hline & 2 & $87.1 \%$ \\
\hline
\end{tabular}

smoking (87.1\%) and a healthy diet $(46.5 \%)$ were the most common healthy behaviours. Table 1 demonstrates each LS7 frequency in the population. The only statistically significant correlation was a higher BNP level with a lower BMI $(\mathrm{P}<0.05)$ (figure 2a). The other LS7 behaviours (diet, PA, smoking status, blood pressure, glucose and cholesterol ffigure $2 \mathrm{~b}-\mathrm{g}\}$ ) as well as a composite (figure $2 \mathrm{~h}$ ) demonstrated no significant correlation with BNP.
Conclusion Analysis shows that LS7 scores vary widely in those at risk for HF. The areas of prime concern are lack of adherence to physical activity, blood pressure control and maintaining a healthy weight. The failure to show an association between LS7 and BNP might reflect the divergent impact of components of this score on BNP. For example, increasing BMI with reduction in BNP and poor BP score with increasing BNP. This analysis provides two important pieces of information in our effort to provide an overarching approach to HF prevention, firstly, the need to place an emphasis on BP management and a healthy weight but also to target physical activity levels. Secondly, the lack of association between BNP and LS7 score indicates that while BNP remains the ultimate risk indicator, that it does not appear to reflect this aspect of care.

\section{APPROPRIATENESS OF TROPONIN TESTING IN PATIENTS ADMITTED MEDICALLY THOROUGH THE EMERGENCY DEPARTMENT}

K Yadav, E Saghie, N Copty, M Strader, P O'Callaghan. University Hospital Waterford, Ireland

\subsection{6/heartjnl-2021-ICS.51}

Acute myocardial infarction (AMI) is defined as cardiomyocyte necrosis in the clinical setting consistent with myocardial ischaemia. High sensitivity cardiac troponin (hs-cTn) is the gold standard for measuring myocardial cell injury. However, inappropriate hs-cTn testing as part of routine bloods at the triage level in the emergency department (ED) can lead to unnecessary serial testing and further interventions such as invasive coronary angiography. Furthermore, the financial burden and impact on laboratory services must be taken into consideration. Each hs-cTn test costs approximately six euros. Our primary aim was to identify if hs-cTn requests sent through the ED comply with our local guidelines by analysing the subset of patients admitted medically.

We conducted a retrospective audit at University Hospital Waterford (UHW) looking at hs-cTn requests over a random two week period analysing the indication and the diagnostic 